\title{
Impact of the COVID-19 Pandemic on Healthcare Workers' Risk of Infection and Outcomes in a Large, Integrated Health System
}

\author{
Anita D. Misra-Hebert, MD, MPH ${ }^{1,2,3}{ }^{(10}$, Lara Jehi, MD, MHCDS ${ }^{4,5}$, Xinge Ji, MS ${ }^{3}$, \\ Amy S. Nowacki, PhD³, Steven Gordon, MD ${ }^{6}$, Paul Terpeluk, DO7, Mina K. Chung, MD ${ }^{8}$, \\ Reena Mehra, MD ${ }^{9}$, Katherine M. Dell, MD ${ }^{10}$, Nathan Pennell, MD, PhD ${ }^{17}$, \\ Aaron Hamilton, MD, MBA ${ }^{12}$, Alex Milinovich, $B A^{3}$, Michael W. Kattan, $P h D^{3}$, and \\ James B. Young, $M D^{2,8}$
}

\begin{abstract}
'Department of Internal Medicine, Cleveland Clinic, Cleveland, OH, USA; ${ }^{2}$ Healthcare Delivery and Implementation Science Center, Cleveland Clinic, Cleveland, OH, USA; ${ }^{3}$ Department of Quantitative Health Sciences, Cleveland Clinic, Cleveland, OH, USA; ${ }^{4}$ Department of Neurology, Cleveland Clinic, Cleveland, OH, USA; Information Technology Division Administration, Cleveland Clinic, Cleveland, OH, USA; ${ }^{5}$ Department of Infectious Disease, Cleveland Clinic, Cleveland, OH, USA; ${ }^{7}$ Department of Occupational Health, Cleveland Clinic, Cleveland, OH, USA; ${ }^{8}$ Department of Cardiovascular Medicine, Cleveland Clinic, Cleveland, OH, USA; ${ }^{9}$ Sleep Disorders Center, Cleveland Clinic, Cleveland, OH, USA; ${ }^{10} \mathrm{Center}$ for Pediatric Nephrology, Cleveland Clinic Children's Hospital, Cleveland, OH, USA; "'Department of Hematology and Oncology, Cleveland Clinic, Cleveland, OH, USA; ${ }^{12}$ Department of Hospital Medicine, Cleveland Clinic, Cleveland, OH, USA.
\end{abstract}

BACKGROUND: Understanding the impact of the COVID19 pandemic on healthcare workers (HCW) is crucial. OBJECTIVE: Utilizing a health system COVID-19 research registry, we assessed HCW risk for COVID-19 infection, hospitalization, and intensive care unit (ICU) admission.

DESIGN: Retrospective cohort study with overlap propensity score weighting.

PARTICIPANTS: Individuals tested for SARS-CoV-2 infection in a large academic healthcare system $(N=72,909)$ from March 8-June 9, 2020, stratified by HCW and patient-facing status.

MAIN MEASURES: SARS-CoV-2 test result, hospitalization, and ICU admission for COVID-19 infection.

KEY RESULTS: Of 72,909 individuals tested, 9.0\% (551) of $6145 \mathrm{HCW}$ tested positive for SARS-CoV-2 compared to $6.5 \%$ (4353) of 66,764 non-HCW. The HCW were younger than the non-HCW (median age 39.7 vs. 57.5, $p<0.001$ ) with more females (proportion of males 21.5 vs. $44.9 \%$, $p<0.001$ ), higher reporting of COVID-19 exposure (72 vs. $17 \%, p<0.001$ ), and fewer comorbidities. However, the overlap propensity score weighted proportions were 8.9 vs. 7.7 for HCW vs. non-HCW having a positive test with weighted odds ratio (OR) $1.17,95 \%$ confidence interval (CI) 0.99-1.38. Among those testing positive, weighted proportions for hospitalization were 7.4 vs. 15.9 for $\mathrm{HCW}$ vs. non-HCW with OR of 0.42 (CI 0.26-0.66) and for ICU admission: 2.2 vs. 4.5 for HCW vs. non-HCW with OR of 0.48 (CI 0.20-1.04). Those HCW identified as patient facing compared to not had increased odds of a positive SARS-CoV-2 test (OR 1.60, CI 1.08-2.39, proportions

Electronic supplementary material The online version of this article (https://doi.org/10.1007/s11606-020-06171-9) contains supplementary material, which is available to authorized users.

Received August 1, 2020

Accepted August 17, 2020

Published online September 1, 2020
8.6 vs. 5.5), but no statistically significant increase in hospitalization (OR 0.88, CI 0.20-3.66, proportions 10.2 vs. 11.4) and ICU admission (OR 0.34, CI 0.01-3.97, proportions 1.8 vs. 5.2).

CONCLUSIONS: In a large healthcare system, HCW had similar odds for testing SARS-CoV-2 positive, but lower odds of hospitalization compared to non-HCW. Patientfacing HCW had higher odds of a positive test. These results are key to understanding $\mathrm{HCW}$ risk mitigation during the COVID-19 pandemic.

KEY WORDS: SARS coronavirus; healthcare workers; employee health.

J Gen Intern Med 35(1 1):3293-301

DOI: $10.1007 / \mathrm{s} 11606-020-06171-9$

(c) Society of General Internal Medicine 2020

\section{INTRODUCTION}

Understanding the risks associated with the COVID-19 pandemic $^{1}$ on healthcare workers (HCW), including the risk of acquisition at work vs. other settings, is crucial. Prediction of risk can inform how to protect $\mathrm{HCW}$ such as recommendations on use of personal protective equipment (PPE) at work or in the community. The presence of specific symptoms in HCW (China, USA $)^{2,3}$ and symptoms predicting SARS-CoV-2 test positivity in HCW (Netherlands) ${ }^{4}$ has been reported as well as characteristics associated with HCW deaths (China). ${ }^{5}$ Based upon data from the 2018 National Health Interview Survey, it was estimated that $26.6 \%$ of patient-facing HCW were at increased risk for poor outcomes from COVID-19 infection because of their comorbidities or age. ${ }^{6}$ Reported experiences in China, ${ }^{7}$ Italy, ${ }^{8}$ and Solano County, CA, without initial use of PPE, ${ }^{9}$ showed higher percentages of $\mathrm{HCW}$ testing positive for COVID-19. In contrast, a screening study of HCW in England showed no significant difference in positive results between 
clinical and nonclinical staff with implementation of isolation and PPE protocols perhaps suggesting predominant community rather than nosocomial transmission patterns. ${ }^{10}$ The extent of risk modification with PPE remains unclear. ${ }^{7-9,11}$ A recent prospective study in the UK and USA suggested a fivefold increased risk for HCW caring for patients with COVID-19 compared to HCW not caring for patients with COVID19 , even with the use of PPE, ${ }^{12}$ while another study of $\mathrm{HCW}$ in a large healthcare system showed a decrease in positive tests for SARS-CoV-2 associated with a universal masking recommendation. ${ }^{13}$ This heterogeneous landscape makes it difficult for the $\mathrm{HCW}$ community to determine actual risk of acquiring COVID-19 in healthcare vs. community settings and the effectiveness of various risk-mitigating strategies.

The Cleveland Clinic Health System (CCHS) is a large, integrated health system with 55,574 eligible employees in Ohio and Florida. The CCHS initiated multiple COVID-19related public health initiatives to mitigate the spread of the disease and its impact on the HCW community. In parallel, we maintained a rigorous, comprehensive, and prospective registry capturing disease risk and progression in all individuals tested for COVID-19 in our health system. In this study, we aimed to assess whether HCW are at higher risk for COVID19 infection, COVID-19-related hospitalization, and intensive care unit (ICU) admission compared to non-HCW using advanced statistical methodology to account for various confounders.

\section{METHODS}

\section{Cohort Definition}

COVID-19 Cleveland Clinic enterprise registry. All patients, regardless of age, who were tested for COVID-19 at all CCHS locations in Ohio and Florida, were included in this research registry. For this study, all individuals who were tested for COVID-19 in the CCHS between March 8, 2020, and June 9, 2020, were studied. This registry provides better representation of the overall population than testing restricted to one geographic health system site. Registry variables were chosen to reflect available literature on COVID-19 disease characterization, progression, and proposed treatments, including medications initially thought to have potential for benefit after drug-repurposing network analysis. ${ }^{14}$ Capture of detailed research data was facilitated by the creation of standardized clinical templates implemented across the healthcare system as patients were seeking care for COVID-19-related concerns. Data were extracted via previously validated automated feeds from electronic health records ${ }^{15}$ (EPIC; EPIC Systems Corporation) and manually by a study team trained on uniform sources for the study variables. Study data were collected and managed using REDCap electronic data capture tools hosted at the Cleveland Clinic. ${ }^{16,17}$ The COVID-19 Research
Registry team includes a "Reviewer" group and a "Quality Assurance" group. The reviewers were responsible for manually abstracting and entering a subset of variables that cannot be automatically extracted from the electronic health record (EHR). Reviewers were also asked to verify high-priority variables that have been automatically pulled into the database from EPIC. The Cleveland Clinic Institutional Review Board approved this study and waived the requirements for written informed consent.

Identification of $\mathbf{H C W}$. Individuals were identified as $\mathrm{HCW}$ through the CCHS Occupational Health, and their job description was identified as having direct contact with patients or "patient facing" vs. non-patient facing based upon the listing in the CCHS Human Resources database.

\section{Public Health and Employer-Initiated Risk-Mitigation Measures}

Public health guidelines for CCHS employees and availability of testing for COVID-19 changed rapidly between March 6, 2020, and April 24, 2020 (Appendix 1), the most relevant being the recommendation for universal masking for CCHS employees on April 7, 2020, and requirement on April 24, 2020. Regarding state public health orders, a stay-at-home order was issued in Ohio on March 22, 2020, with phased reopening in May starting with restaurants and bars on May $14,2020,{ }^{18}$ and in Florida, a public health advisory was issued on March 25, 2020, addressing vulnerable populations, private gatherings, and workforce density ${ }^{19}$ with reopening beginning on May $18,2020 .^{20}$

\section{Statistical Analysis}

All descriptive statistics were reported as counts (percentages) or median (interquartile ranges [IQRs]). For comparison of demographic variables and comorbidities among cohorts, Wilcoxon signed-rank tests were used for numeric variables, while $\chi^{2}$ or Fisher exact tests were used for categorical variables. To address differences in baseline characteristics of non-HCW and HCW, specifically as related to underlying comorbidities, and the limitations of current literature that failed to account for such differences, we leveraged appropriate statistical methodology to study our research questions. Overlap propensity score ${ }^{21,22}$ weighting was performed to address potential confounding in comparing $\mathrm{HCW}$ to non$\mathrm{HCW}$ given their baseline differences. The overlap propensity score weighting method was chosen given its benefits of preservation of numbers of individuals in each group and of achieving higher levels of precision in the resulting estimates. This methodology is preferred when the propensity score distributions among the groups are dissimilar and when the propensity scores are clustered near the extremes (i.e., close to zero or one). A propensity score for being a $\mathrm{HCW}$ was 
estimated from a multivariable logistic regression model. For the outcome of being test positive for COVID-19, the propensity score logistic regression model included covariates that were found to be associated with a positive COVID-19 test outcome in our previous work. ${ }^{23}$ For the outcomes of hospital and intensive care unit (ICU) admission of COVID-19 testpositive patients, the propensity score covariates are those that were found associated with COVID-19 hospitalization outcome in our previous work including age, race, ethnicity, gender, smoking history, body mass index, median income, population per housing unit, presenting symptoms (including fever, fatigue, shortness of breath, diarrhea, vomiting), comorbidities (including asthma, hypertension, diabetes, immunosuppressive disease), medications (including immunosuppressive treatment, nonsteroidal anti-inflammatory drugs [NSAIDs]), and laboratory values (including pre-testing platelets, aspartate aminotransferase, blood urea nitrogen, chloride, and potassium).

The overlap propensity score weighting method was then applied where each patient's statistical weight is the probability of that patient being assigned to the opposite group. ${ }^{21}$ Overlap propensity score weighted logistic regression models were used to investigate associations between $\mathrm{HCW}$ status and the probability of testing positive for SARS-CoV-2, hospital admission for COVID-19, and ICU admission for COVID-19 illness. The results are thus reported as weighted proportions, odds ratios, and $95 \%$ confidence intervals. All statistical analyses were performed using R 3.5 and SAS version 9.4 (SAS Institute). $P$ values were 2 -sided, with a significance threshold of 0.05 .

We then used locally weighted regression smoother (LOESS) to summarize the trend of COVID-19 test positivity through the study period for $\mathrm{HCW}$ and non-HCW as related to the public health measures instituted at the state level and those specific to the CCHS.

\section{RESULTS}

Overall tested cohort characteristics. Of the 72,909 individuals tested for COVID-19 in the CCHS Research Registry, there were $6145 \mathrm{HCW}$ and 66,764 non-HCW with over $90 \%$ of HCW and $75 \%$ of non-HCW tested from Ohio. There were $9 \%$ of HCW who tested positive for COVID-19 compared to $6.5 \%$ of non-HCW, $p<0.001$ (Table 1). The HCW tested were younger than the non-HCW (median age $39.7 \mathrm{vs.}$ $57.5, p<0.001$ ) with more females (proportion of males 21.5 vs. $44.9 \%, p<0.001$ ), higher proportion of Asian and lower proportion of Black persons (3.4 vs. $1.0 \%$ and 16.2 vs. $18.3 \%$, respectively, $p<0.001$ ), higher proportion identifying as nonHispanic ( 90.8 vs. $87.6 \%, p<0.001)$, higher median income, and higher proportion of nonsmokers. The neighborhood characteristic of population density as measured per square kilometer was similar for tested $\mathrm{HCW}$ vs. non-HCW while the population per housing unit was slightly higher. The HCW were more likely to report an exposure to COVID-19 (72.0\% vs. $17.0 \%, p<0.001)$ and also to report having a family member with COVID-19 (28.3 vs. 14.2\%, $p$ 0.005). Regarding presenting symptoms, a slightly higher proportion of HCW reported cough (32.0 vs. $29.6 \%, p$ 0.001), a lower proportion reported fever $(15.0$ vs. $19.5 \%, p<0.001)$ or shortness of breath (14.6 vs. $25.7 \%, p<0.001)$, while a higher proportion reported diarrhea $(11.9$ vs. $9.5 \%, p<0.001)$ and a lower proportion reported vomiting $(7.4$ vs. $9.7 \%, p<0.001)$. Of note, the tested HCW were, in general, healthier than the non-HCW group. The HCW had a lower proportion of several comorbidities including chronic obstructive pulmonary disease(COPD)/emphysema, diabetes, hypertension, coronary artery disease, heart failure, cancer, history of transplant, or immunosuppressive disease and were more likely to have received the influenza vaccine ( 85.9 vs. $45.4 \%, p<0.001)$. The HCW tested had a lower proportion of previous prescriptions for immunosuppressive treatment, NSAIDs, steroids, carvedilol, angiotensin-converting enzyme inhibitors, angiotensin receptor blockers, or melatonin.

COVID-19 cohort characteristics and outcomes. There were $551 \mathrm{HCW}$ and 4353 non-HCW who tested positive for COVID-19 (Appendix Table 1). Of those who tested positive for COVID-19, a lower proportion of HCW were hospitalized compared to non-HCW (38 or $6.9 \% \mathrm{HCW}$ vs. 1205 or $27.7 \%$ non-HCW) or were admitted to the intensive care unit (10 or $1.8 \% \mathrm{HCW}$ vs. 470 or $10.8 \%$ non-HCW). In the group who tested positive for COVID-19, there was a greater proportion of HCW of Asian and White race compared to non-HCW (2.9 vs. $0.8 \%$ and 61.0 vs $56.4 \%$, respectively); a similar proportion of HCW with a positive COVID-19 test had presenting symptoms of cough, fatigue, diarrhea, loss of appetite, and vomiting; and a lower proportion had fever or shortness of breath. Lower proportions of HCW testing positive had COP$\mathrm{D} / \mathrm{emphysema}$, diabetes, coronary artery disease, heart failure, cancer, or immunosuppressive disease and were previously prescribed carvedilol, angiotensin-converting enzyme inhibitors, angiotensin receptor blockers, or melatonin compared to non-HCW. The neighborhood population characteristics of population density or population per housing unit did not differ for those HCW who tested positive and median income was slightly higher compared to non-HCW.

Overlap propensity weighting. Using the variables in the prediction model for COVID-19 test positivity, ${ }^{23}$ overlap propensity score weighting (Table 2) resulted in propensity score weighted proportions of 7.7 vs. 8.9 for non-HCW vs. HCW having a positive test and produced an overlap propensity score weighted odds ratio of 1.17 with a $95 \%$ confidence interval (CI) of $0.99-1.38$ for a $\mathrm{HCW}$ having a positive test compared to a non-HCW (Fig. 1a). Then using the variables 
Table 1 Characteristics of All Patients Tested for SARS-CoV-2 by Healthcare Worker (HCW) Status

\begin{tabular}{|c|c|c|c|}
\hline & $\begin{array}{l}\text { Non-HCW } \\
\text { Number }(\%) \text { or median } \\
\text { [interquartile range] }\end{array}$ & $\begin{array}{l}\text { HCW } \\
\text { Number }(\%) \text { or median } \\
\text { [interquartile range] }\end{array}$ & $p$ value \\
\hline Number & 66,764 & 6145 & \\
\hline SARS-CoV-2 positive & $4353(6.5)$ & $551(9.0)$ & $<0.001$ \\
\hline \multicolumn{4}{|l|}{ Demographics } \\
\hline Ohio & $50,204(75.2)$ & $5642(91.8)$ & $<0.001$ \\
\hline Florida & $13,957(20.9)$ & $503(8.2)$ & \\
\hline \multirow{2}{*}{\multicolumn{3}{|c|}{ Race }} & \\
\hline & & & $<0.001$ \\
\hline Asian & $672(1.0)$ & $206(3.4)$ & \\
\hline Black & $12,201(18.3)$ & $995(16.2)$ & \\
\hline Other & $5394(8.1)$ & $490(8.0)$ & \\
\hline White & $48,497(72.6)$ & $4454(72.5)$ & \\
\hline Male & $29,959(44.9)$ & $1322(21.5)$ & $<0.001$ \\
\hline Non-Hispanic & $58,496(87.6)$ & $5577(90.8)$ & $<0.001$ \\
\hline \multicolumn{3}{|l|}{ Smoking } & $<0.001$ \\
\hline Current smoker & $9316(14.0)$ & $147(2.4)$ & \\
\hline Former smoker & $30,196(45.2)$ & $1737(28.3)$ & \\
\hline No & $27,048(40.5)$ & 4259 (69.3) & \\
\hline Unknown & $204(0.3)$ & $2(0.0)$ & \\
\hline Age & $57.53[39.32,70.26]$ & $39.67[31.29,51.80]$ & $<0.001$ \\
\hline \multicolumn{4}{|l|}{ Exposure history } \\
\hline Exposed to COVID-19 & $11,369(17.0)$ & $4424(72.0)$ & $<0.001$ \\
\hline Family member with COVID-19 & $9503(14.2)$ & $1740(28.3)$ & $<0.001$ \\
\hline \multicolumn{4}{|l|}{ Presenting symptoms } \\
\hline Cough & $19,744(29.6)$ & $1968(32.0)$ & 0.001 \\
\hline Fever & $12,997(19.5)$ & $922(15.0)$ & $<0.001$ \\
\hline Fatigue & $8020(12.0)$ & $637(10.4)$ & $<0.001$ \\
\hline Sputum production & $402(0.6)$ & $45(0.7)$ & 0.244 \\
\hline Flu-like symptoms & 5949 (8.9) & $423(6.9)$ & $<0.001$ \\
\hline Shortness of breath & $17,133(25.7)$ & 898 (14.6) & $<0.001$ \\
\hline Diarrhea & $6335(9.5)$ & $731(11.9)$ & $<0.001$ \\
\hline Loss of appetite & $1505(2.3)$ & $299(4.9)$ & $<0.001$ \\
\hline Vomiting & $6471(9.7)$ & $454(7.4)$ & $<0.001$ \\
\hline \multicolumn{4}{|l|}{ Comorbidities } \\
\hline Body mass index & $28.37[25.85,31.07]$ & $28.37[27.37,29.13]$ & $<0.001$ \\
\hline Chronic obstructive & $8247(12.4)$ & $166(2.7)$ & $<0.001$ \\
\hline \multicolumn{4}{|l|}{ pulmonary disease/emphysema } \\
\hline Asthma & $12,057(18.1)$ & 1343 (21.9) & $<0.001$ \\
\hline Diabetes & $13,418(20.1)$ & $428(7.0)$ & $<0.001$ \\
\hline Hypertension & $30,727(46.0)$ & $1505(24.5)$ & $<0.001$ \\
\hline Coronary artery disease & $10,181(15.2)$ & $204(3.3)$ & $<0.001$ \\
\hline Heart failure & $8192(12.3)$ & $93(1.5)$ & $<0.001$ \\
\hline Cancer & $12,469(18.7)$ & $646(10.5)$ & $<0.001$ \\
\hline Transplant history & $1120(1.7)$ & $19(0.3)$ & $<0.001$ \\
\hline Multiple sclerosis & $493(0.7)$ & $43(0.7)$ & 0.794 \\
\hline Connective tissue disease & $2376(3.6)$ & $178(2.9)$ & 0.008 \\
\hline Inflammatory bowel disease & $1604(2.4)$ & $112(1.8)$ & 0.005 \\
\hline Immunosuppressive disease & $10,375(15.5)$ & $414(6.7)$ & $<0.001$ \\
\hline \multicolumn{4}{|l|}{ Vaccination history } \\
\hline Influenza vaccine & $30,340(45.4)$ & $5277(85.9)$ & $<0.001$ \\
\hline Pneumococcal polysaccharide vaccine & $17,808(26.7)$ & $451(7.3)$ & $<0.001$ \\
\hline \multicolumn{4}{|l|}{ Laboratory findings upon presentation } \\
\hline Pre-testing platelets & $238.00[238.00,238.00]$ & $238.00[238.00,238.00]$ & 0.137 \\
\hline Pre-testing AST & $23.00[23.00,23.00]$ & $23.00[23.00,23.00]$ & 0.051 \\
\hline Pre-testing BUN & $16.00[16.00,16.00]$ & $16.00[16.00,16.00]$ & $<0.001$ \\
\hline Pre-testing chloride & $101.00[101.00,101.00]$ & $101.00[101.00,101.00]$ & 0.092 \\
\hline Pre-testing creatinine & $0.92[0.92,0.92]$ & $0.92[0.92,0.92]$ & $<0.001$ \\
\hline Pre-testing hematocrit & $39.50[39.50,39.50]$ & $39.50[39.50,39.50]$ & 0.41 \\
\hline Pre-testing potassium & $4.10[4.10,4.10]$ & $4.10[4.10,4.10]$ & 0.081 \\
\hline \multicolumn{4}{|l|}{ Home medications } \\
\hline Immunosuppressive treatment & $2392(3.6)$ & $270(4.4)$ & $<0.001$ \\
\hline Nonsteroidal anti-inflammatory drugs & $19,651(29.4)$ & $1048(17.1)$ & $<0.001$ \\
\hline Steroids & $11,838(17.7)$ & 969 (15.8) & $<0.001$ \\
\hline Carvedilol & $2803(4.2)$ & $40(0.7)$ & $<0.001$ \\
\hline Angiotensin-converting enzyme inhibitor & 7568 (11.3) & $329(5.4)$ & $<0.001$ \\
\hline Angiotensin receptor blocker & $5698(8.5)$ & $228(3.7)$ & $<0.001$ \\
\hline Melatonin & 3078 (4.6) & $52(0.8)$ & $<0.001$ \\
\hline \multicolumn{4}{|l|}{ Social influencers of health } \\
\hline Population per $\mathrm{km}^{2}$ & $3.03[2.63,3.29]$ & $3.01[2.64,3.28]$ & 0.568 \\
\hline Median income per $\$ 1000$ & $58.09[41.62,76.21]$ & $64.78[49.78,85.54]$ & $<0.001$ \\
\hline Population per housing unit & $2.22[1.93,2.49]$ & $2.26[2.01,2.51]$ & $<0.001$ \\
\hline
\end{tabular}


Table 2 All Tested Patients: Overlap Propensity Score-Weighted Characteristics

\begin{tabular}{|c|c|c|}
\hline & Non-HCW & HCW \\
\hline Count & 66,764 & 6145 \\
\hline \multicolumn{3}{|l|}{ Race } \\
\hline Asian & 2.3 & 2.3 \\
\hline Black & 17.9 & 17.9 \\
\hline Other & 8 & 8 \\
\hline White & 71.8 & 71.8 \\
\hline Male & 25.1 & 25.1 \\
\hline Non-Hispanic & 90.2 & 90.2 \\
\hline \multicolumn{3}{|l|}{ Smoking } \\
\hline Current smoker & 3.7 & 3.7 \\
\hline Former smoker & 31.7 & 31.7 \\
\hline No & 64.6 & 64.6 \\
\hline Unknown & 0 & 0 \\
\hline Age & 43.38 & 43.38 \\
\hline Exposed to COVID-19 & 58.1 & 58.1 \\
\hline Family member with COVID-19 & 0.1 & 0.1 \\
\hline Cough & 34.4 & 34.4 \\
\hline Fever & 18 & 18 \\
\hline Fatigue & 11.7 & 11.7 \\
\hline Sputum production & 0.9 & 0.9 \\
\hline Flu-like symptoms & 7.3 & 7.3 \\
\hline Diarrhea & 12.7 & 12.7 \\
\hline Loss of appetite & 4.3 & 4.3 \\
\hline Vomiting & 8.7 & 8.7 \\
\hline Asthma & 22.9 & 22.9 \\
\hline Coronary artery disease & 4.6 & 4.6 \\
\hline Transplant history & 0.5 & 0.5 \\
\hline Connective tissue disease & 3.4 & 3.4 \\
\hline Inflammatory bowel disease & 2.1 & 2.1 \\
\hline Influenza vaccine & 79.2 & 79.2 \\
\hline Pneumococcal polysaccharide vaccine & 11.3 & 11.3 \\
\hline Pre-testing platelets & 240.05 & 240.05 \\
\hline Pre-testing aspartate aminotransferase & 23.87 & 23.87 \\
\hline Pre-testing chloride & 101.05 & 101.05 \\
\hline Pre-testing creatinine & 0.92 & 0.92 \\
\hline Pre-testing hematocrit & 39.48 & 39.48 \\
\hline Pre-testing potassium & 4.09 & 4.09 \\
\hline Nonsteroidal anti-inflammatory drugs & 20.4 & 20.4 \\
\hline Steroids & 17.4 & 17.4 \\
\hline Carvedilol & 0.9 & 0.9 \\
\hline Angiotensin-converting enzyme inhibitor & 6.7 & 6.7 \\
\hline Angiotensin receptor blocker & 4.9 & 4.9 \\
\hline Melatonin & 1.2 & 1.2 \\
\hline Population per $\mathrm{km}^{2}$ & 2.92 & 2.92 \\
\hline Median income (thousands of dollars) & 68.20 & 68.20 \\
\hline Body mass index & 2.92 & 2.92 \\
\hline Final result $=$ positive test for $S A R S-C o V-2$ & 7.7 & 8.9 \\
\hline Odds ratio (95\% confidence interval) & & $1.17(0.99,1.38)$ \\
\hline
\end{tabular}

Reported are either weighted proportions (for categorical variables) or weighted means (for numeric variables)

which predicted hospitalization for COVID-19 infection, overlap propensity score weighting was applied (Table 3 ) with weighted proportions for being hospitalized 15.9 vs. 7.4 for non-HCW vs. HCW, an odds ratio of 0.42 (CI $0.26-0.66$ ) for a HCW being hospitalized for COVID-19 compared to a nonHCW. For ICU admission, weighted proportions were 4.5 vs. 2.2 for non-HCW vs. HCW with an odds ratio of 0.48 (CI $0.20-1.04$ ) for HCW being admitted to the ICU compared to non-HCW (Fig. 1a).

\section{Subgroup Analysis}

We then compared characteristics of HCW identified as having positions that required direct contact with patients ("patient facing") and those that did not. There were 5159 HCW with patient-facing positions and $986 \mathrm{HCW}$ in nonpatient-facing roles (Appendix Table 3). The HCW with patient-facing roles were younger (median age 38 vs. 47 years, $p<0.001$ ), with more females (proportion males 20.6 vs. $26.2 \%, p<0.001$ ), lower proportion of Black race and higher Asian race, and with greater proportion reporting exposure to COVID-19 (73.7 vs. $62.9 \%, p<0.001$ ). The patient-facing HCW had lower proportions presenting with fatigue or shortness of breath and higher proportion with loss of appetite. There were no significant differences in laboratory values upon presentation. The patient-facing $\mathrm{HCW}$ had lower proportions of some previously prescribed medications including NSAIDs, steroids, angiotensin-converting enzyme inhibitors, angiotensin 
a

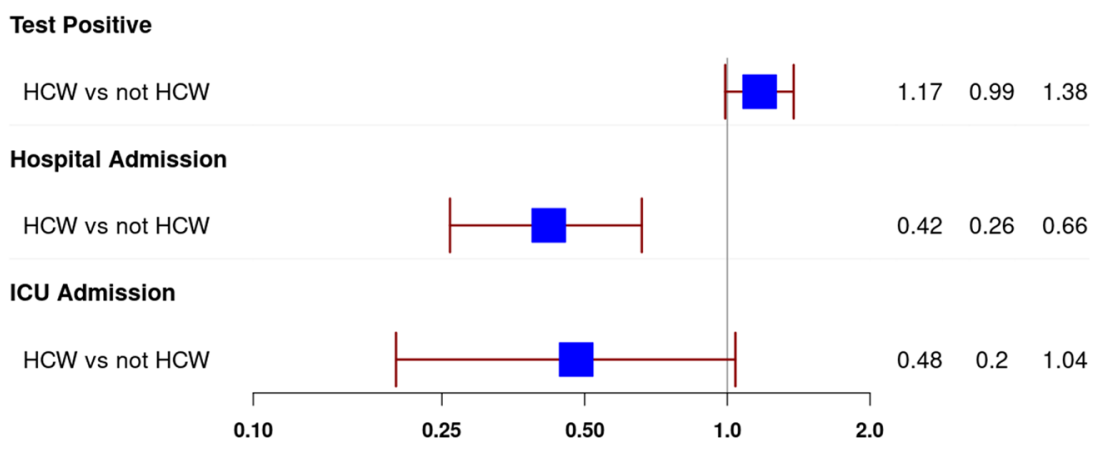

b

Test Positive

Patient Facing vs not Patient Facing

Hospital Admission

Patient Facing vs not Patient Facing

ICU Admission

Patient Facing vs not Patient Facing
OR LCL UCL

OR LCL UCL

$\begin{array}{lll}1.60 & 1.08 & 2.39\end{array}$

$0.88 \quad 0.20 \quad 3.66$

$\begin{array}{lll}0.34 & 0.01 \quad 3.97\end{array}$

Figure 1 a Odds of SARS-CoV-2 positive test; hospital admission if SARS-CoV-2 positive and intensive care admission if SARS-CoV-2 positive by healthcare worker (HCW) status. b Odds of SARS-CoV-2 positive test; hospital admission if SARS-CoV-2 positive and intensive care admission if SARS-CoV-2 positive by patient-facing and non-patient-facing healthcare worker status. $O R=0 d$ ds ratio, $L C L=l o w e r ~ c o n f i d e n c e$ limit, $\mathbf{U C L}=$ upper confidence limit.

receptor blockers, and melatonin. The patient-facing HCW group had lower proportions of comorbidities including COPD/emphysema, diabetes, hypertension, coronary artery disease, cancer, connective tissue disease, and immunosuppressive disease. Applying the overlap propensity score weighting (Appendix Tables 4 and 5; Fig. 1b) showed patient-facing $\mathrm{HCW}$ with increased odds of having a positive SARS-CoV-2 test result (OR 1.60, CI 1.08-2.39, weighted proportions 8.6 vs. 5.5), and lower but nonsignificant odds of hospital admission (OR 0.88, CI $0.20-3.66$, proportions 10.2 vs. 11.4) and ICU admission (OR 0.34, CI 0.013.97, proportions 1.8 vs. 5.2).

\section{Temporal Relationship between Disease Prevention Measures and Positive Tests}

The summary of the trend of SARS-CoV-2 positive test results in the study period is shown in Figure 2. The overall proportion of positive COVID-19 test results decreased during the study period and the trend for $\mathrm{HCW}$ and followed that of non-HCW.

\section{DISCUSSION}

Our analysis of HCW compared to non-HCW who were tested for SARS-CoV-2 in one health system with 2 geographic locations (Ohio, Florida), and which controlled for significant differences in baseline characteristics between the HCW and non-HCW groups, showed that the odds of having a positive COVID-19 test were not significantly different for HCW compared to non-HCW, and HCW had lower odds of subsequent hospitalization, and without statistically significant differences in ICU admission compared to non-HCW once they tested positive. The HCW classified as having patient-facing positions had higher and significant odds of a positive COVID-19 test with insignificant differences detected compared to non-patient-facing HCW in outcomes of hospitalization or ICU admission. We found a similar proportion of HCW with a positive COVID-19 test had presenting symptoms of cough, fatigue, diarrhea, loss of appetite, and vomiting while a lower proportion had fever or shortness of breath. We note that we were not able to capture the symptoms of loss of taste and/or smell and that these symptoms may be common especially with mild cases of COVID-19. ${ }^{24,25}$ 
Table 3 All Test Positive Patients: Overlap Propensity Score-Weighted Characteristics

\begin{tabular}{|c|c|c|}
\hline & Non-HCW & HCW \\
\hline Count & 4353 & 551 \\
\hline \multicolumn{3}{|l|}{ Race } \\
\hline Asian & 2.1 & 2.1 \\
\hline Black & 28.6 & 28.6 \\
\hline Other & 9.4 & 9.4 \\
\hline White & 59.9 & 59.9 \\
\hline Male & 30.7 & 30.7 \\
\hline \multicolumn{3}{|l|}{ Ethnicity } \\
\hline Hispanic & 3.3 & 3.3 \\
\hline Non-Hispanic & 90.2 & 90.2 \\
\hline Unknown & 6.4 & 6.4 \\
\hline \multicolumn{3}{|l|}{ Smoking } \\
\hline Current smoker & 2.9 & 2.9 \\
\hline Former smoker & 18.6 & 18.6 \\
\hline No & 73.7 & 73.7 \\
\hline Unknown & 4.8 & 4.8 \\
\hline Age & 43.50 & 43.50 \\
\hline Fever & 44.8 & 44.8 \\
\hline Fatigue & 55.2 & 55.2 \\
\hline Shortness of breath & 37 & 37 \\
\hline Diarrhea & 35 & 35 \\
\hline Vomiting & 24.7 & 24.7 \\
\hline Asthma & 12.6 & 12.6 \\
\hline Diabetes & 10.4 & 10.4 \\
\hline Hypertension & 22.2 & 22.2 \\
\hline Immunosuppressive treatment & 6.9 & 6.9 \\
\hline Immunosuppressive disease & 4.5 & 4.5 \\
\hline Pre-testing platelets & 234.70 & 234.70 \\
\hline Pre-testing aspartate aminotransferase & 24.51 & 24.51 \\
\hline Pre-testing blood urea nitrogen & 15.76 & 15.76 \\
\hline Pre-testing chloride & 100.04 & 100.04 \\
\hline Pre-testing potassium & 3.99 & 3.99 \\
\hline Nonsteroidal anti-inflammatory drugs & 17.4 & 17.4 \\
\hline Median income (thousands of dollars) & 62.25 & 62.25 \\
\hline Population per housing unit & 2.22 & 2.22 \\
\hline Body mass index & 29.63 & 29.63 \\
\hline Final result $=$ hospitalization & 15.9 & 7.4 \\
\hline Odds ratio (95\% confidence interval) & & $0.42(0.26,0.66)$ \\
\hline Intensive care unit admission & 4.5 & 2.2 \\
\hline Odds ratio (95\% confidence interval) & & $0.48(0.20,1.04)$ \\
\hline
\end{tabular}

Reported are either weighted proportions (for categorical variables) or weighted means (for numeric variables)

The overall proportion of COVID-19 positive tests in $\mathrm{HCW}$ was low and decreased during the study period corresponding with implementation of risk-mitigation measures in our health system such as the recommendations for universal masking and physical distancing but also followed the trend for non-HCW. Several of the previous studies of $\mathrm{HCW}$ risk for infection during the COVID-19 pandemic were limited by their sample sizes, ${ }^{7-9}$ lack of generalizability for healthcare systems that have adequate access to PPE ${ }^{7-9}$ methodology relying on self-report, ${ }^{12}$ limited ability to adjust for known risk factors of disease susceptibility and progression, ${ }^{7-10,12}$ and lacking data to investigate the relative effects of dual exposure of HCW to COVID-19 in the community versus the workplace. $^{7-10,12}$ The fact that $\mathrm{HCW}$ identified as patient facing had a significantly higher odds for SARSCoV-2 test positivity suggests an increased risk of COVID-19 infection with work exposure. However, it is important to note in our study that over $70 \%$ of the $\mathrm{HCW}$ group reported an exposure to COVID-19 with $28 \%$ reporting exposure to a family member with COVID-19. In our study, we were not able to confirm if the patientfacing $\mathrm{HCW}$ were working in patient-facing areas during the 14-day period before the test was ordered when exposure could have occurred, or whether the exposure occurred with or without PPE-both in the workplace or in the community, or the relative contribution of initially prioritizing testing availability to $\mathrm{HCW}$ with reported exposures. While the risk to $\mathrm{HCW}$ attributed to community spread may not be captured in our available data, the reported exposure risk including the higher proportion of $\mathrm{HCW}$ vs. non-HCW reporting exposure to a family member with COVID-19 suggests a degree of community acquisition of infection. A potential contributing factor to community acquisition is that $\mathrm{HCW}$, particularly patient-facing $\mathrm{HCW}$, are less able to follow stay-at- 


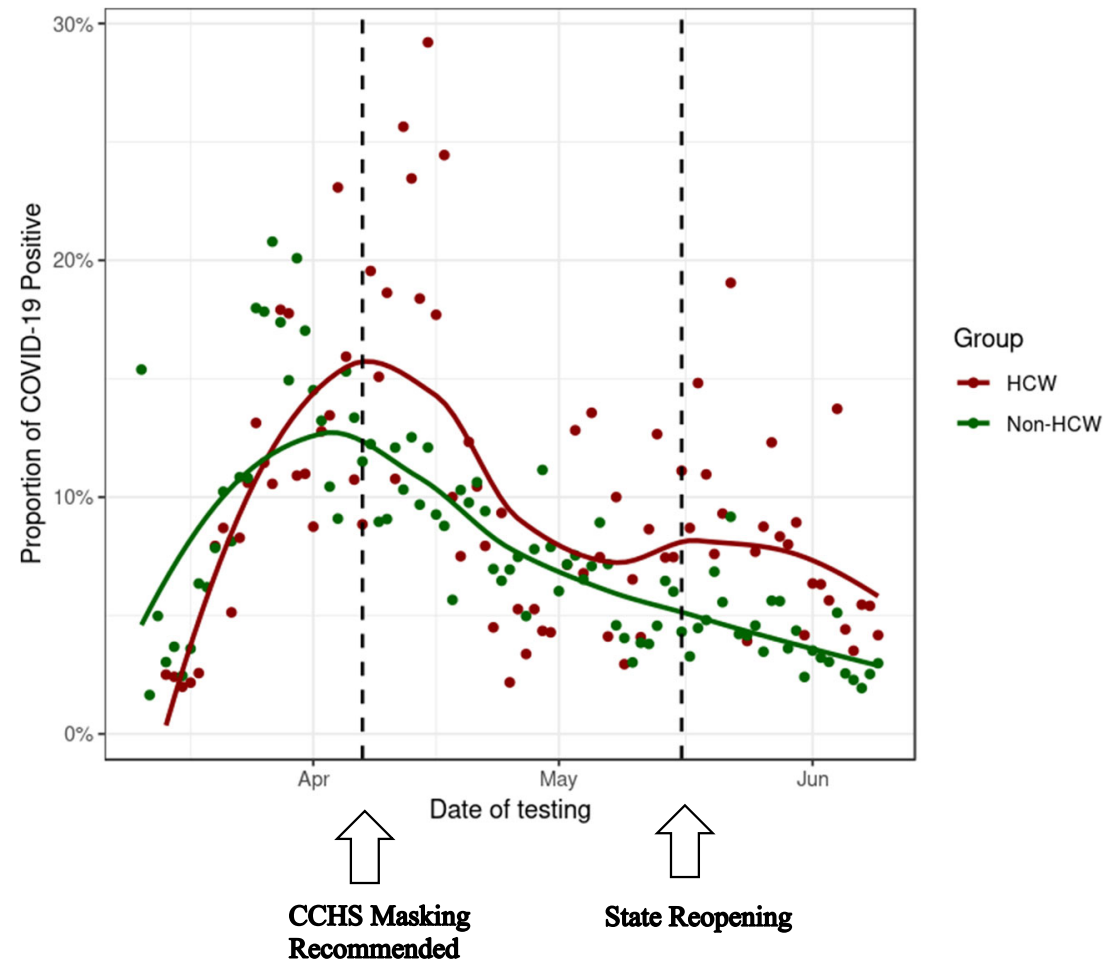

Figure 2 Proportion of SARS-CoV-2 positive results during the study period. CCHS $=$ Cleveland Clinic Health System.

home guidelines or work remotely from home. Indeed, while PPE use is associated with decreased risk of infection from coronavirus, ${ }^{26}$ a recent report estimated less than $5 \%$ risk to $\mathrm{HCW}$ inadvertently exposed to patients not known to be SARS-CoV-2-positive at the time of initial exposure with exposure likely occurring without appropriate $\mathrm{PPE}^{27}$ suggesting that the work exposure risk may actually be low. However, universal pandemic precautions have been recommended for optimal risk mitigation for $\mathrm{HCW}^{28}$

\section{CONCLUSION}

In our analysis of one healthcare system which implemented significant risk-mitigation strategies to prevent the spread of COVID-19 infection, and which controlled for significant baseline differences in HCW compared to non-HCW, the odds for SARS-CoV-2 infection were similar for HCW and nonHCW and HCW had lower odds for COVID-19-related hospitalization. The patient-facing $\mathrm{HCW}$ had higher odds of SARS-CoV-2 infection.

Corresponding Author: Anita D. Misra-Hebert, MD, MPH; Department of Internal Medicine, Cleveland Clinic, Cleveland, OH, USA (e-mail:misraa@ccf.org).

Funding Information Dr. Misra-Hebert receives funding from the Agency for Healthcare Research and Quality grant \# KO8HSO24128 and reports grants from NHLBI, grants from Novo Nordisk, Inc., grants from Merck Inc., and grants from Boehringer Ingelheim Pharmaceuticals, Inc., outside the submitted work. Dr. Jehi receives funding from the National Institute of Neurological Disorders and Stroke RO1 NS097719 and from the National Center for Advancing Translational Science UL1TR002548 outside the submitted work. Dr. Pennell receives consulting fees from Merck, BMS, Eli Lilly, Genentech, AstraZeneca, G1 Therapeutics, and Amgen outside the submitted work. Dr. Chung receives funding from National Institutes of Health grant RO1 HL 111314 and American Heart Association COVID-19 Rapid Response Grant \#814633 outside the submitted work. Mr. Milinovich reports grants from NovoNordisk, Inc., grants from Merck, Inc., grants from Novartis, and grants from Boehringer Ingelheim Pharmaceuticals, Inc., outside the submitted work. Dr. Dell reports research support from NIDDK (R01-DK114425, UO1-DK110988, U01DK066143, U54-DK083912) and NCATS (UL1T-R001445) as well as Amgen, Retrophin, and Atari all outside the submitted work. Dr. Mehra reports receiving National Institutes of Health funding support from the National Heart, Lung, and Blood Institute [UO1HL125177, UG3HL140144] and the American Heart Association, and has received funds for service on the American Board of Medicine Sleep Medicine Exam test writing committee and as Associate Editor of the American Journal of Respiratory and Critical Care Medicine and royalties from UpToDate.

\section{Compliance with Ethical Standards:}

Conflict of Interest: The authors declare that they do not have a conflict of interest.

\section{REFERENCES}

1. CDC. Coronavirus disease 2019 (COVID-19). Centers for Disease Control and Prevention. Published February 11, 2020. Accessed May 20, 2020. https://www.cdc.gov/coronavirus/2019-ncov/index.html

2. Wang X, Liu W, Zhao J, et al. Clinical characteristics of 80 hospitalized frontline medical workers infected with COVID-19 in Wuhan, China, J Hosp Infect. 2020; https://doi.org/10.1016/j.jhin.2020.04.019 
3. CDC COVID-19 Response Team. Characteristics of health care personnel with COVID-19 - United States, February 12-April 9, 2020. MMWR Morb Mortal Wkly Rep. 2020;69(15):477-481. https://doi.org/10.15585/ mmwr.mm6915e6

4. Tostmann A, Bradley J, Bousema T, et al. Strong associations and moderate predictive value of early symptoms for SARS-CoV-2 test positivity among healthcare workers, the Netherlands, March 2020. Euro Surveill. 2020;25(16). https://doi.org/10.2807/1560-7917.ES.2020.25. 16.2000508

5. Li W, Zhang J, Xiao S, Sun L. Characteristics of deaths amongst health workers in China during the outbreak of COVID-19 infection. J Infect. 2020; https://doi.org/10.1016/j.jinf.2020.03.030

6. Himmelstein DU, Woolhandler $\mathbf{S}$. Health insurance status and risk factors for poor outcomes with COVID-19 among U.S. health care workers: a cross-sectional study. Ann Intern Med. 2020; https://doi. org/10.7326/M20-1874

7. Wu Z, McGoogan JM. Characteristics of and important lessons from the coronavirus disease 2019 (COVID-19) outbreak in China: summary of a report of 72314 cases from the Chinese Center for Disease Control and Prevention. JAMA. 2020; https://doi.org/10. 1001/jama.2020.2648

8. Bellizzi S, Fiamma M, Arru L, Farina G, Manca A. Covid-19: the daunting experience of health workers in Sardinia, Italy. Infect Control Hosp Epidemiol. 2020:1-5; https://doi.org/10.1017/ice.2020.149

9. Heinzerling A, Stuckey MJ, Scheuer T, et al. Transmission of COVID-19 to health care personnel during exposures to a hospitalized patient - Solano County, California, February 2020. MMWR Morb Mortal Wkly Rep. 2020;69(15):472-476. https://doi.org/10.15585/mmwr.mm6915e5

10. Hunter E, Price DA, Murphy E, et al. First experience of COVID-19 screening of health-care workers in England. Lancet. 2020; https://doi. org/10.1016/S0140-6736(20)30970-3

11. Chou R, Dana T, Jungbauer R, Weeks C, McDonagh MS. Masks for prevention of respiratory virus infections, including SARS-CoV-2, in health care and community settings. Ann Intern Med. 2020; https:// doi.org/10.7326/M20-3213

12. Nguyen LH, Drew DA, Joshi AD, et al. Risk of COVID-19 among frontline healthcare workers and the general community: a prospective cohort study. MedRxiv Prepr Serv Health Sci. 2020; https://doi.org/10. $1101 / 2020.04 .29 .20084111$

13. Wang X, Ferro EG, Zhou G, Hashimoto D, Bhatt DL. Association between universal masking in a health care system and SARS-CoV-2 positivity among health care workers. JAMA. 2020; https://doi.org/10. 1001/jama.2020.12897

14. Network-based drug repurposing for novel coronavirus 2019-nCoV/ SARS-CoV-2 | Cell Discovery. Accessed July 10, 2020. https://www. nature.com/articles/s41421-020-0153-3

15. Milinovich A, Kattan MW. Extracting and utilizing electronic health data from Epic for research. Ann Transl Med. 2018;6(3):42. https://doi.org/ $10.21037 /$ atm.2018.01.13
16. Harris PA, Taylor R, Thielke R, Payne J, Gonzalez N, Conde JG Research electronic data capture (REDCap)-a metadata-driven methodology and workflow process for providing translational research informatics support. J Biomed Inform. 2009;42(2):377-381. https://doi.org/10. 1016/j.jbi.2008.08.010

17. PubMed entry. Accessed July 10, 2020. http://www.ncbi.nlm.nih.gov/ pubmed/31078660

18. Public health orders. Accessed July 23, 2020. https://coronavirus.ohio. gov/wps/portal/gov/covid-19/responsible-restart-ohio/Public-HealthOrders/

19. News. Florida Department of Health COVID-19 Outbreak. Accessed July 23, 2020. https://floridahealthcovid19.gov/news/

20. The State of Florida issues COVID-19 updates | Florida Department of Health. Accessed July 23, 2020. http://www.floridahealth.gov/newsroom/2020/05/051720-1648-covid19.pr.html

21. Li F, Thomas LE, Li F. Addressing extreme propensity scores via the overlap weights. Am J Epidemiol. 2018;188(1):250-257. https://doi.org/ 10.1093/aje/kwy201

22. Thomas LE, Bonow RO, Pencina MJ. Understanding observationa treatment comparisons in the setting of coronavirus disease 2019 (COVID-19). JAMA Cardiol. 2020; https://doi.org/10.1001/jamacardio. 2020.1874

23. Jehi L, Ji X, Milinovich A, et al. Individualizing risk prediction for positive COVID-19 testing: results from 11,672 patients. Chest. 2020; https://doi.org/10.1016/j.chest.2020.05.580

24. Dawson P, Rabold EM, Laws RL, et al. Loss of taste and smell as distinguishing symptoms of COVID-19. Clin Infect Dis. 2020; https:// doi.org/10.1093/cid/ciaa799

25. Boscolo-Rizzo P, Borsetto D, Fabbris C, et al. Evolution of altered sense of smell or taste in patients with mildly symptomatic COVID-19. JAMA Otolaryngol Head Neck Surg. 2020; https://doi.org/10.1001/jamaoto. 2020.1379

26. Chou R, Dana T, Buckley DI, Selph S, Fu R, Totten AM Epidemiology of and risk factors for coronavirus infection in health care workers. Ann Intern Med. 2020; https://doi.org/10.7326/ M20-1632

27. Baker MA, Rhee C, Fiumara K, et al. COVID-19 infections among HCWs exposed to a patient with a delayed diagnosis of COVID-19. Infect Control Hosp Epidemiol. Published online undefined/ed:1-2. https://doi.org/10. 1017/ice.2020.256

28. Weber DJ, Babcock H, Hayden MK, et al. Universal pandemic precautions-an idea ripe for the times. Infect Control Hosp Epidemiol. Published online undefined/ed:1-2. https://doi.org/10. $1017 /$ ice.2020.327

Publisher's note Springer Nature remains neutral with regard to jurisdictional claims in published maps and institutional affiliations. 